Revista Complutense de Educación

ISSNe: 1988-2793

http://dx.doi.org/10.5209/RCED.59470

\title{
Indicadores Comentados sobre el Estado del Sistema Educativo Español
} 2017

Autores: Ma Auxiliadora Ruiz Rosillo, Miguel Ángel Sancho Gargallo y Mercedes de Esteban Villar

Editorial: Centro de Estudios Ramón Areces

Año de publicación: 2017

$\mathrm{N}^{\mathrm{o}}$ de páginas: 184

ISBN: -

Depósito legal: M-20554-2017

El libro que reseño es un trabajo de exposición de la situación y evolución del sistema educativo español, con una intención comparativa relativa y elaborado a partir de fuentes estadísticas e informes nacionales e internacionales.

Este trabajo es el tercero de una serie de ellos auspiciados por las fundaciones "Ramón Areces" y "Europea Sociedad y Educación". El objetivo no es aportar metodologías científicas de recogida o de análisis de datos, sino más bien seleccionar aquellos datos relevantes disponibles de diversas fuentes para propiciar un debate educativo público informado en España.

Un equipo de comentaristas expertos en educación ha colaborado en identificar aspectos de fortaleza y debilidad de nuestro sistema educativo. Estos colaboradores han sido: Julio Carabaña, Miguel Ángel Sancho Gargallo, Rafael Feito, Miquel Àngel Alegre Canosa, Javier M. Valle, Álvaro Choi, Emma García, Gabriela Sicilia, Pau Marí-Klose, José García Clavel, y Juan Ignacio Martínez Pastor.

La primera parte, La educación en España, recoge datos de la población escolar, el nivel educativo de la población, y la distribución de las tasas de escolarización por enseñanzas, de idoneidad y de graduación.

El segundo bloque, Recursos educativos, recoge el gasto público por alumno y por actividad educativa, y su relación con el PIB; datos relacionados con el profesorado, la ratio y tamaño del aula; el uso de internet y ordenadores en las actividades de enseñanza y aprendizaje; recursos, contexto y organización escolar.

El tercer apartado, Resultados educativos, aporta datos de evolución de España con respecto a los seis objetivos europeos para los sistemas de educación y formación. El abandono educativo temprano y el porcentaje de población que no ha alcanzado educación superior son aspectos prioritarios y diferenciadores de la educación española desde la perspectiva comparada.

La sección Educación y empleo incluye datos relativos a la participación en actividades de aprendizaje permanente; iniciativas nacionales desarrolladas para la promoción del empleo y la formación en los jóvenes, nivel educativo y situación laboral.

La aspiración de ambas fundaciones es familiarizar a los lectores con el modo en que los analistas atienden, explican y analizan las variables que describen el presen- 
te de los sistemas de enseñanza, contribuyendo a orientar el rumbo de la educación española.

Entre las numerosas referencias bibliográficas que se aportan en el libro, hemos seleccionado las dos que más se aproximan a los temas tratados en un despliegue de Tablas y Gráficos que pueden ayudar a valorar visualmente los aspectos tratados. Ambas referencias son del Ministerio de Educación, Cultura y Deporte, de España.

El procesamiento de datos y análisis estadísticos puede realizarse entre otras posibilidades con el programa SPSS en sus distintas versiones, cada vez más mejoradas y actualizadas. En el libro se aprecian también el trabajo de diseño específico en la presentación de los gráficos estadísticos en la versión impresa.

Ochenta gráficos y catorce tablas presentados en el libro es el resultado de un esfuerzo coordinado en la preparación cuidadosa del mismo, aunque se aprecia alguna carencia entre los gráficos.

Aunque parezca que este despliegue desborda las posibilidades de un lector de los contenidos, sí permiten un estudio sosegado en cuestiones concretas tratadas y en el desarrollo de los aspectos más relevantes del estado del sistema de la educación española en el año 2017.

El trabajo es expositivo y también ilustrativo de las realidades encontradas y descritas estadísticamente con una buena intención comparativa por Comunidades Autónomas dentro de España, e internacionalmente.

Las tecnologías usadas en el tratamiento de los datos pueden provenir de diversos orígenes así como las metodologías estadísticas, que no han quedado explicitadas en el libro, algo que tiene interés para los elaboradores técnicos de trabajos similares.

Un buen material de apoyo a los argumentos y al debate de las cuestiones educativas siempre importantes.

\section{Referencias bibliográficas}

Ministerio de Educación, Cultura y Deporte (2016). Datos y Cifras. Curso Escolar 20162017. Edición 2016. Madrid: Subdirección General de Estadística y Estudios. Ministerio de Educación, Cultura y Deporte.

Ministerio de Educación, Cultura y Deporte (2017). Anuario Estadístico. Las Cifras de la Educación en España. Curso 2014-2015. Madrid: Subdirección General de Estadística y Estudios. Ministerio de Educación, Cultura y Deporte.

Mariano Ruiz Espejo ruizesp@gmail.com 